\title{
Risk of endometrial cancer after treatment with oestrogens alone or in conjunction with progestogens: results of a prospective study
}

\author{
Ingemar Persson, Hans-Olov Adami, Leif Bergkvist, Anders Lindgren, Birgitta Pettersson, \\ Robert Hoover, Catherine Schairer
}

\begin{abstract}
Objective-To determine the relative risk of developing endometrial neoplasia after treatment with oestrogens alone or in conjunction with progestogens.
\end{abstract}

Design-Prospective cohort follow up study, average observation period $5 \cdot 7$ years for each patient. To have a $90 \%$ chance of detecting a relative risk of 2.0 with $95 \%$ significance the study required 78000 person years of observation.

Setting-Community based cohort.

Patients-Women aged over 35 who were prescribed non-contraceptive oestrogens in the Uppsala health care region during April 1977 to March 1980 were identified from pharmacy records. Of all prescriptions issued, 95\% were identified. Patients from the cohort who developed endometrial neoplasia were identified from the cancer registry of the Uppsala health care region. Compliance, sociodemographic data, and lifetime exposures to oestrogen and cyclically added progestogen were assessed by questionnaire in a sample of the cohort. The final cohort consisted of 23244 patients (133 373 person years). The prevalence of university education, oophorectomy, and hysterectomy was higher in the cohort than the general population; no other confounding factors were identified.

Measurements - The total number of person years was divided into exposure groups by inference from the data from the questionnaire. Compensation was made for the excess of hysterectomies. Specimens from all cases of endometrial neoplasia in the cohort and $90 \%$ of cases in the general population were studied blind histopathologically. Characteristics of treatment of all women who had endometrial neoplasia were assessed by questionnaire. Relative risks and $95 \%$ confidence intervals were calculated.

Results-Seventy four cases of carcinoma and 33 cases of premalignant lesions occurred in the cohort. The relative risk of endometrial carcinoma was 1.8 (95\% confidence interval $1 \cdot 1$ to $3 \cdot 2$ ) after exposure to any oestrogen compound without progestogen for more than six years; $2.2(1.2$ to 4.4$)$ after more than three years' exposure to conjugated oestrogens without progestogen; and $2.7(1.4$ to $5 \cdot 1)$ after more than three years' exposure to oestradiol compounds without progestogen. When carcinoma and premalignant lesions were considered together the results were similar but the relative risk was higher. Risk of carcinoma did not increase when progestogens were cyclically added to oestrogens for the entire treatment period (relative risk $0.9(0.4$ to 2.0$)$ ).

Conclusions-Use of oestrogens without progestogens is associated with a twofold to threefold increase in risk of endometrial neoplasia. Use of progestogens either removes this increased risk or delays its onset. A further follow up of the cohort is essential to analyse the risks with greater statistical power.

\section{Introduction}

Case-control studies have provided evidence of an increase in the risk of developing endometrial cancer dependent on the dose and duration of exposure to conjugated oestrogens without concomitant use of progestogens.' The wide variation in estimates of overall risk, which range from a twofold to a 12 -fold increase, has been attributed to differences in methodology, including the histopathological criteria of cancer used, selection of cases and controls, definition of exposure, and dose and duration of treatment. Although the validity of the results of these retrospective studies has been debated, ${ }^{2}$ a true, causal association is considered to exist.

Progestogens added for at least 10 days of each treatment cycle have been shown to protect against endometrial hyperplasia,${ }^{4}$ and a combined regimen is now commonly used to treat women who have not had their uterus removed. Epidemiological data have been too scarce to show whether adding progestogens can prevent endometrial cancers after long term treatment.

We report the results of the first six years of a large prospective investigation of a population based cohort that was designed to analyse the risk of endometrial cancer with special regard to duration and type of exposure to oestrogen and to the presence of added progestogens. It is the first epidemiological study of sufficient size to evaluate the effects of the combined regimen of oestrogens and progestogens on risk of cancer and to use an unbiased histopathological classification of all cases of cancer.

\section{Methods}

The case-cohort approach was used for this investigation. ${ }^{6}$ A large cohort of women who had been prescribed non-contraceptive oestrogens for menopausal problems was defined by information from their prescription forms. A programme designed to detect and report all prescription forms for such drugs was started in April 1977 and continued until the end of March 1980. It included all 120 pharmacies in the Uppsala health care region, which serves one sixth of the Swedish population. Records of the amounts of oestrogen compounds (defined daily doses ${ }^{7}$ ) sold in the region indicated that it would be possible to recruit some 25000 women given treatment during these three years. To have a $90 \%$ chance of detecting a twofold increase in risk of endometrial cancer (a relative risk of $2 \cdot 0$ ) at a $95 \%$ significance level (with two sided tests), and given a baseline incidence of endometrial cancer in Sweden of $50 / 100000$, a study base of about 78000 
person years was necessary. ${ }^{\times}$Thus a follow up of more than three years would be expected to yield a cohort of adequate size to show this increase in risk.

A pilot study showed that the pharmacies reported $95 \%$ of all prescriptions. About 77000 prescriptions were identified. Two sets of data were taken from the prescription forms: the national registration number was used to identify and follow up each woman, and data on the type of oestrogen, dose and frequency of administration, and date of purchase were used to characterise each exposure to oestrogen.

The cohort finally comprised 23244 women who had had one or more prescriptions for drugs containing oestrogen during April 1977 to March 1980, were aged 35 or older when they bought the first recorded prescription, and lived in the defined region. ${ }^{\prime}$ The national registration numbers of all subjects were matched with those of all women newly diagnosed as having cancer or premalignancy of the endometrium, identified from the cancer registry of the Uppsala health care region. In this way all cases in the cohort within the region were ascertained.

\section{DETERMINATION OF EXPOSURE TO OESTROGEN}

To obtain comprehensive information on exposure to oestrogen and progestogen during the patient's lifetime and to describe the prevalence of relevant risk factors for endometrial cancer in the cohort a questionnaire was sent to 735 randomly selected members of the cohort (those born on the fifth day of the month) early in 1980 and again in 1984. The size of this subcohort was determined by financial constraints and by power considerations so as to obtain an acceptable ratio of women with endometrial cancer to women in the subcohort and thus a high relative efficiency within the case-cohort design." The first questionnaire elicited an $89 \%$ response rate $(653 / 735)$ and provided extensive information on exposure to oestrogen and progestogen as well as characteristics of patients. ${ }^{10} 11$ The second questionnaire was answered by $84 \%$ of the previous respondents (549/653) and provided information on episodes of treatment with oestrogen to the end of 1983.

The questionnaires showed that $91 \%(592 / 653)$ of the respondents had taken the prescribed oestrogenic drug, that $45 \%$ (296) of them had started treatment before 1977, and that $21 \%$ (137) were still taking oestrogen at the end of 1983. Oestradiol compounds (oestradiol valerate and ethinyloestradiol) accounted for $56 \%$ of treatments, conjugated oestrogens for $22 \%$, and other oestrogens, including oestriol compounds, for $23 \%$. Progestogen had been added (usually for seven to 10 days of each cycle) in $31 \%$ of all treatment episodes. ${ }^{10}$

Information about intake of hormones before and after the period during which prescriptions were recorded was obtained by questionnaire for all women in the cohort who developed endometrial neoplasia. For the 84 diagnosed from 1977 to the end of September 1982 the questionnaire was given to the patient on admission to hospital, and for the 23 diagnosed thereafter the questionnaire was posted to the patient before admission. Seventeen (16\%) of the 107 women in whom a malignant or premalignant lesion was diagnosed during the follow up period to 1983 did not reply. They were allocated to groups according to the distribution of drug treatments in women with a lesion of corresponding ages for whom such information had been obtained. Exposure of women with endometrial neoplasia who did not reply was thus classified in the same way as exposure of non-respondents in the cohort.

\section{DATA ANALYSIS}

The starting point of observation of all cohort members was the purchase date of the first reported prescription, and the end point was the date of death, dated diagnosis of a premalignant lesion or cancer, or December 1983. The numbers of person years were calculated according to duration of exposure, type of oestrogen compounds, and presence of progestogen by inference from proportions found in the sample given the questionnaires. Changes in exposure classification as follow up continued were calculated with the occupational cohort mortality program (OCMAP). Patients with endometrial neoplasia and person years were divided into five exposure groups: oestrogen only, oestrogen taken solely in conjunction with progestogen, oestrogen with progestogen preceded by less than five years of oestrogen alone, oestrogen with progestogen preceded by more than five years of oestrogen alone, and other combinations of treatment. For women who used oestrogen both alone and with progestogen the number of person years in each category was determined by the date of switch.

The expected number of cases of endometrial neoplasia was obtained by multiplying the accumulated person years of follow up by the five year age specific incidence. These incidences were calculated from the 545 cases of endometrial neoplasia that had occurred from 1980 to 1983 inclusive in the background population (that is, not including the cases observed and person years accumulated in the cohort). An independent and blinded histopathological review of slides of tissue from $490(90 \%)$ of the women with endometrial neoplasia in the background population and from all 107 in the cohort allowed diagnostic criteria to be standardised. Of the slides examined in the background population, $426(87 \%)$ were classified as showing cancer and $64(13 \%)$ as showing premalignant lesions (endometrial dysplasia with varying degrees of cellular atypia including carcinoma in $\left.\operatorname{situ}^{13}\right)$ whereas in the cohort $74(69 \%)$ slides showed cancer and $33(31 \%)$ premalignant lesions. ${ }^{1+}$

Relative risk (the ratio of observed to expected cases) was used as the measure of association. ${ }^{15}$ Estimates of the number of person years in the total cohort were made from the randomly selected subcohort who had been sent questionnaires. To deal with the added variability in the estimation of the relative risk $95 \%$ confidence intervals were calculated according to a method developed for case-cohort studies using external comparisons, which took into account the variability in both the observed and expected numbers of cases."

To evaluate the possibility that the distribution of risk factors for endometrial cancer in the cohort was different from that in the background population a questionnaire study was also performed among 1240 women from the background population. ${ }^{16}$ This did not show any differences in the prevalence of diabetes, hypertension, or nulliparity; the distribution of heigh and weight; or age at menarche and menopause. A higher proportion of the women who were prescribed oestrogen had a university education than did women in the background population $(7.7 \% v 4.0 \% ; \mathrm{p}<0.05)$ In addition, oophorectomies and hysterectomies were four times and twice as common among the women given oestrogen than among the background population. The higher prevalence of hysterectomies in the cohort was adjusted for by reducing the person years at risk in the cohort by the margin of difference between the cohort and background population for each age group.

\section{Results}

From April 1977 to the end of 1983, 23244 women entered the study and 883 died. This population contributed 133373 person years of follow up, an 
average of $5 \cdot 7$ years per person. Nine per cent ( 12183$)$ of the person years were contributed by women who had been prescribed but had not taken oestrogen, $55 \%$ (72641) by women who had taken oestrogen for three years or less, and 36\% (48549) by women who had taken oestrogen for more than three years. Women exposed to combinations of oestrogen and progestogen accounted for $26 \%$ ( 35318 ) of the person years.

Altogether 74 cases of endometrial cancer were observed compared with $55 \cdot 7$ expected, yielding a relative risk of $1.3(95 \%$ confidence interval 1.0 to $1 \cdot 7)$. Ten of these women denied taking oestrogen; among them the expected number of cases of endometrial cancer was $7 \cdot 0$, giving a relative risk of $1 \cdot 4(0 \cdot 4$ to $2 \cdot 1)$.

Among the women who took oestrogen the relative risks were computed with regard to duration of use and presence or absence of added progestogen (table I). For

TABLE I-Relative risk of endometrial cancer after exposure to oestrogen alone or with cyclically added progestogen during the entire treatment, according to duration of treatment

\begin{tabular}{|c|c|c|c|c|c|c|}
\hline \multirow[b]{2}{*}{$\begin{array}{l}\text { Duration of } \\
\text { treatment } \\
\text { (months) }\end{array}$} & \multicolumn{3}{|c|}{ Oestrogen alone } & \multicolumn{3}{|c|}{ Oestrogen with progestogen } \\
\hline & $\begin{array}{c}\begin{array}{c}\text { No of } \\
\text { cases } \\
\text { observed }\end{array} \\
\end{array}$ & $\begin{array}{c}\begin{array}{c}\text { No of } \\
\text { cases } \\
\text { expected }\end{array} \\
\end{array}$ & $\begin{array}{c}\text { Relative risk } \\
\text { (95\% confidence } \\
\text { interval) }\end{array}$ & $\begin{array}{c}\text { No of } \\
\text { cases } \\
\text { observed }\end{array}$ & $\begin{array}{c}\text { No of } \\
\text { cases } \\
\text { expected }\end{array}$ & $\begin{array}{c}\text { Relative risk } \\
\text { (95\% confidence } \\
\text { interval) }\end{array}$ \\
\hline$\leqslant 6$ & 6 & $5 \cdot 5$ & $1.1(0.5$ to 2.5$)$ & 0 & $1 \cdot 7$ & $0 \quad(0.0$ to $12 \cdot 7)$ \\
\hline $7-36$ & 16 & $11 \cdot 3$ & $1.4(0.8$ to 2.4$)$ & 5 & $3 \cdot 6$ & $1.4(0.5$ to 3.6$)$ \\
\hline $37-72$ & 11 & $9 \cdot 3$ & $1.2(0.6$ to 2.2$)$ & 2 & $1 \cdot 7$ & $1.2(0.3$ to 5.5$)$ \\
\hline$\geqslant 73$ & 15 & $8 \cdot 2$ & $1.8 \quad(1.1$ to 3.2$)$ & 0 & $0 \cdot 6$ & $0 \quad(0.0$ to $456 \cdot 1)$ \\
\hline Total & 48 & $34 \cdot 3$ & $1.4(1.1$ to 1.9$)$ & 7 & $7 \cdot 6$ & $0.9(0.4$ to 2.0$)$ \\
\hline
\end{tabular}

TABLE II - Relative risk of endometrial cancer or premalignant lesions after exposure to oestrogen alone or with cyclically added progestogen during the entire treatment, according to duration of treatment

\begin{tabular}{|c|c|c|c|c|c|c|}
\hline \multirow[b]{2}{*}{$\begin{array}{l}\text { Duration of } \\
\text { treatment } \\
\text { (months) }\end{array}$} & \multicolumn{3}{|c|}{ Oestrogen alone } & \multicolumn{3}{|c|}{ Oestrogen with progestogen } \\
\hline & $\begin{array}{c}\text { No of } \\
\text { cases } \\
\text { observed }\end{array}$ & $\begin{array}{c}\text { No of } \\
\text { cases } \\
\text { expected }\end{array}$ & $\begin{array}{c}\text { Relative risk } \\
\text { (95\% confidence } \\
\text { interval) }\end{array}$ & $\begin{array}{c}\text { No of } \\
\text { cases } \\
\text { observed }\end{array}$ & $\begin{array}{l}\text { No of } \\
\text { cases } \\
\text { expected }\end{array}$ & $\begin{array}{c}\text { Relative risk } \\
\text { (95\% confidence } \\
\text { interval) }\end{array}$ \\
\hline$\leqslant 6$ & 6 & $6 \cdot 6$ & $0.9(0.4$ to $2 \cdot 1)$ & 2 & $2 \cdot 3$ & $0.9(0.2$ to $4 \cdot 3)$ \\
\hline $7-36$ & 22 & $14 \cdot 0$ & $1.6(1.0$ to 2.5$)$ & 8 & $5 \cdot 0$ & $1.6(0.7$ to 3.5$)$ \\
\hline $37-72$ & 18 & $11 \cdot 3$ & $1.6(1.0$ to 2.6$)$ & 2 & $2 \cdot 3$ & $0.9(0.2$ to 4.1$)$ \\
\hline$\geqslant 73$ & 26 & $9 \cdot 5$ & $2.7(1.8$ to 4.2$)$ & 0 & $0 \cdot 7$ & $0 \quad(0.0$ to 211.8$)$ \\
\hline Total & 72 & $41 \cdot 4$ & $1 \cdot 7(1 \cdot 4$ to $2 \cdot 2)$ & 12 & $10 \cdot 2$ & $1 \cdot 2(0.6$ to $2 \cdot 1)$ \\
\hline
\end{tabular}

treatment with oestrogen alone the overall risk of endometrial cancer was increased (relative risk $1 \cdot 4(1 \cdot 1$ to 1.9)). There was evidence of a duration-response gradient, the relative risk estimates rising to $1 \cdot 8(1 \cdot 1$ to $3 \cdot 2)$ in women exposed to oestrogen for longer than six years. Exposure to oestrogen solely in conjunction with progestogen did not increase the risk (relative risk 0.9 $(0 \cdot 4$ to $2 \cdot 0))$. Nine of the women with endometrial cancer had taken oestrogen both alone and with progestogen: in five treatment with progestogen had been preceded by less than five years of oestrogen alone (relative risk $1.3(0.5$ to 3.6$)$ ) and in three by more than five years of oestrogen alone (relative risk $5 \cdot 7(0 \cdot 1$ to 249.7)), and in one treatment was in another pattern (relative risk $0 \cdot 4(0 \cdot 1$ to $3 \cdot 2)$ ).

When premalignant lesions were considered as well, 107 cases of endometrial neoplasia were observed compared with $68 \cdot 1$ expected (relative risk $1.6(1 \cdot 3$ to 1.9)); among the women who did not take oestrogen 11 cases were observed compared with $7 \cdot 9$ expected (relative risk $1 \cdot 4(0 \cdot 5$ to $2 \cdot 5))$. Among women who had taken oestrogen similar patterns of risk were seen, but at slightly higher levels (table II). The relative risks for treatment with oestrogen alone were $1 \cdot 7(1 \cdot 4$ to $2 \cdot 2)$ overall and $2.7(1.8$ to 4.2$)$ after more than six years, whereas treatment with oestrogen solely in conjunction with progestogen was not associated with a significantly increased risk (relative risk $1.2(0.6$ to $2 \cdot 1))$. Treatment with oestrogen and progestogen was preceded by less than five years of treatment with oestrogen alone in six cases (relative risk $1.2(0.5$ to 3.0$)$ ) and by a longer period in four cases (relative risk $6 \cdot 6(0 \cdot 2$ to $285 \cdot 9)$ ). Two women had a different combination of treatment (relative risk $0 \cdot 7(0 \cdot 2$ to $2 \cdot 9)$ ).

The two outcomes (endometrial cancer only or all cases, including premalignant lesions) were analysed by type of oestrogenic compounds among women in the cohort who took oestrogen. Oestradiol compounds and conjugated oestrogens, when taken for more than three years without progestogen, were associated with a twofold to threefold increase in the risk of endometrial neoplasia, whereas other oestrogens were not (tables III and IV).

TABLE IV-Relative risk of endometrial cancer or premalignant lesions after exposure to various types of oestrogenic compounds alone or with progestogen during the entire treatment, according to duration of treatment

\begin{tabular}{|c|c|c|c|c|c|c|c|}
\hline \multirow[b]{2}{*}{$\begin{array}{l}\text { Type of } \\
\text { oestrogen } \\
\text { compound }\end{array}$} & \multirow[b]{2}{*}{$\begin{array}{c}\text { Duration of } \\
\text { treatment } \\
\text { (months) }\end{array}$} & \multicolumn{3}{|c|}{ Oestrogen alone } & \multicolumn{3}{|c|}{ Oestrogen with progestogen } \\
\hline & & $\begin{array}{c}\text { No of } \\
\text { cases } \\
\text { observed }\end{array}$ & $\begin{array}{l}\text { No of } \\
\text { cases } \\
\text { expected }\end{array}$ & $\begin{array}{c}\text { Relative risk } \\
\text { (95\% confidence } \\
\text { interval) }\end{array}$ & $\begin{array}{c}\text { No of } \\
\text { cases } \\
\text { observed }\end{array}$ & $\begin{array}{c}\text { No of } \\
\text { cases } \\
\text { expected }\end{array}$ & $\begin{array}{c}\text { Relative risk } \\
\text { (95\% confidence } \\
\text { interval) }\end{array}$ \\
\hline Oestradiol & $\begin{array}{l}\leqslant 36 \\
\geqslant 37 \\
\text { Total }\end{array}$ & $\begin{array}{l}20 \\
18 \\
38\end{array}$ & $\begin{array}{r}11 \cdot 1 \\
6 \cdot 6 \\
17 \cdot 7\end{array}$ & $\begin{array}{l}1.8(1.1 \text { to } 2.9) \\
2.7(1.5 \text { to } 5.0) \\
2.1(1.5 \text { to } 3.0)\end{array}$ & $\begin{array}{r}12 \\
2 \\
14\end{array}$ & $\begin{array}{c}9 \cdot 5 \\
3 \cdot 4 \\
12 \cdot 9\end{array}$ & $\begin{array}{l}1.3(0.7 \text { to } 2.3) \\
0.6(0.1 \text { to } 2.6) \\
1.1(0.6 \text { to } 1.9)\end{array}$ \\
\hline Conjugated oestrogens & $\begin{array}{l}\leqslant 36 \\
\geqslant 37 \\
\text { Total }\end{array}$ & $\begin{array}{l}15 \\
21 \\
36\end{array}$ & $\begin{array}{r}8 \cdot 1 \\
7 \cdot 1 \\
15 \cdot 2\end{array}$ & $\begin{array}{l}1.9(1.0 \text { to } 3.4) \\
3.0(1.7 \text { to } 5.3) \\
2.4(1.7 \text { to } 3.4)\end{array}$ & $\begin{array}{l}0 \\
1 \\
1\end{array}$ & $\begin{array}{l}1.0 \\
0.7 \\
1 \cdot 7\end{array}$ & $\begin{array}{l}0 \quad(0.0 \text { to } 90.0) \\
1.4(0.0 \text { to } 80.5) \\
0.6(0.1 \text { to } 5.9)\end{array}$ \\
\hline Other oestrogens & $\begin{array}{l}\leqslant 36 \\
\geqslant 37 \\
\text { Total }\end{array}$ & $\begin{array}{r}19 \\
8 \\
27\end{array}$ & $\begin{array}{r}16 \cdot 9 \\
7 \cdot 7 \\
24 \cdot 6\end{array}$ & $\begin{array}{l}1.1(0.7 \text { to } 1.8) \\
1.0(0.5 \text { to } 2.2) \\
1.1(0.7 \text { to } 1.6)\end{array}$ & & & \\
\hline
\end{tabular}


A duration-response relation was present with higher risk estimates when oestrogen had been taken for more than three years compared with shorter periods. Treatment with oestrogen alone resulted in an increased risk of neoplasia after less than three years' exposure to oestradiol and conjugated estrogens (relative risk 1.8 ( 1.1 to 2.9$)$ and $1.9(1.0$ to 3.4$)$ respectively) (table IV). Neither of the two compounds was associated with an increased risk when taken with progestogen. Women who took oestradiol for more than three years and received progestogen for only part of this time had an increased risk of endometrial neoplasia (relative risk $2 \cdot 4(1 \cdot 1$ to $5 \cdot 6))$.

\section{Discussion}

The results of this study confirm an increase in the risk of endometrial cancer associated with a long duration of treatment with potent oestrogenic drugs, such as oestradiol and conjugated oestrogens, without concomitant progestogens. We found similar patterns and higher estimates of risk when premalignant lesions were included in the analysis. This study also provides preliminary evidence of the benefits of adding progestogen when oestrogens are given. No increase in risk was noted for women taking only such regimens, and there was a tendency for the women who had received mixed regimens (oestrogen treatment with and without progestogen) and who had a relatively longer duration of combined treatment, to have lower risks of endometrial neoplasia. Our data do not indicate, however, that added progestogen can prevent all endometrial neoplasia from developing in women treated with oestrogen. Furthermore, all the excess risk did not seem to be averted when progestogen was added if oestrogen alone had been used previously.

It must be recognised that in some instances - that is, for women given long term treatment with oestrogen and progestogen - the analyses were based on small numbers of cases and person years and therefore have wide confidence limits and limited statistical power. After the women who did not take the prescribed oestrogenic drugs or who had had hysterectomies and were thus not at risk of endometrial cancer were excluded from the cohort a study base of about 100100 person years of follow up remained. This base gave more than a $90 \%$ chance of detecting an overall excess risk of twofold or greater, given two sided $95 \%$ confidence intervals and an average baseline incidence of $50 / 100000 .^{8}$ Among women exposed to any oestrogen compound for more than three years without added progestogen there was a $90 \%$ power to show an increased risk of threefold or greater, whereas among women given such long term treatment with oestrogen and progestogen the increase in risk would need to be fivefold or greater to be detected at this power. Thus the present study base did not provide adequate statistical power to reject the null hypothesis if there was an increased risk or to yield narrow confidence intervals if there was no increased risk among women given oestrogen with progestogen in the long term. The patterns of the risk estimates, however, consistently support there being no excess risk of endometrial cancer with such treatment. These are the first epidemiological data that pertain to the effects of oestrogens given with progestogen on the risk of endometrial neoplasia. Furthermore, the present results agree with the finding of short term clinical studies that cyclically added progestogen protects against the development of endometrial hyperplasia and atypical hyperplasia. ${ }^{+}$As the follow up of the cohort continues the study base will be enlarged, leading to greater statistical power and allowing firmer conclusions to be drawn.

The blinded review of the histopathological speci- mens provided an unbiased diagnostic classification of the cases of endometrial neoplasia included in the analyses. All had been derived from a population based cancer register, in which $96 \%$ of cases among the cohort and in the background population had been reported and coded as cancers, the remaining $4 \%$ being coded as premalignant lesions. The review resulted in the reclassification as premalignant lesions of a substantially higher proportion of cancers among the cohort than the background population. ${ }^{14}$ This is probably because most endometrial cancers that occur after exposure to oestrogen are found at an early clinical stage, are of a low grade, and are rarely more than superficially invasive into the myometrium'; in such cases it is difficult to establish firm morphological criteria for distinguishing between premalignant and malignant endometrial lesions. ${ }^{13}$ Therefore, some of the cases classified as premalignant lesions might be regarded as cancers by other examiners. ${ }^{14}$

Cases classified in the review as cancers were analysed separately from and together with those regarded as premalignant lesions. The results of both analyses agree with those from numerous retrospective case-control studies from the United States that report an increased risk of early endometrial cancer after two to four years of exposure to conjugated oestrogens given without progestogen. ${ }^{3}$

\section{METHODOLOGICAL PROBLEMS}

We used the case-cohort design to keep costs at a minimum while maintaining the basic advantages of a cohort study with efficient follow up through record linkage with a population based cancer register. None the less, some methodological problems could have affected the validity of the results.

Losses to follow up due to migration from the region were estimated by ascertaining the current domicile of a random sample of 742 of the 23344 women, of whom $15(2.0 \%$ of those still alive in 1988 , five years after the end of the study) were no longer resident in the region. Assuming that this proportion of the entire cohort was lost to follow up after an average of three years of observation, we underestimated the observed outcome by no more than two cases.

Details of compliance with treatment, total duration of exposure to oestrogen, and the addition of progestogen among the entire cohort relied on data from questionnaires. The reliability of these exposure histories was checked against the available prescription forms during the three years for which prescriptions were collected and found to be satisfactory. ${ }^{17}$ The details of treatment with oestrogen for all women from the cohort who had endometrial neoplasia were determined shortly after diagnosis, during the first five and a half years by a questionnaire administered in the hospital and later in the study by a posted questionnaire. Such unequal ascertainment of data could introduce a bias, but this is unlikely to have been substantial as the correlation between the duration of exposure reported on questionnaires and obtained from prescriptions was as good among these women $(r=0.92)$ as among the sample from the cohort $(\mathrm{r}=0 \cdot 98) .{ }^{17}$

As exposure to oestrogen in the cohort was estimated from replies to questionnaires of a sample from the cohort $(653 / 735)$ and from 90 of the 107 women with neoplasia the representativeness of these respondents had to be evaluated. From the national registration number on the prescription forms we determined that the women who did not respond were slightly older than those who did (mean ages $57.8 v 56.0$ and $62.3 v$ 59.5 years respectively). The estimated duration of exposure to oestrogens (determined from prescriptions issued during the three year period) was slightly shorter for women who did not respond than for those 
who did in the sample from the cohort $(11.0 v 15.4$ months) but was somewhat longer for women with endometrial neoplasia who did not respond to the questionnaire than for those who did (21.4 $v 17 \cdot 7)$. These differences could have led to a slight overestimate of expected cases and an underestimate of observed cases among women exposed to oestrogen in the long term and thereby to a possible underestimate of the true excess risk. The magnitude of such a bias would, however, be negligible as the estimated differences were small and only $11 \%$ of the cohort sample and $17 \%$ of the women with neoplasia did not respond.

The possibility of the cohort being confounded with regard to risk factors for endometrial neoplasia gained no support, as no important differences from the background population other than a higher educational level and a higher prevalence of hysterectomy were found in the cohort. The adjustment for different rates of hysterectomy by reducing the person years at risk among age groups in the cohort may leave some residual bias. If women who had had hysterectomies were more likely to have taken oestrogen without progestogen in the long term, proportionally more person years should have been removed in these exposure categories. If such a bias was present the increased risk after long durations of treatment with oestrogen without progestogen would have been underestimated in this study.

It has been suggested that asymptomatic endometrial cancers are more likely to be diagnosed among women treated with oestrogen than among those not treated with oestrogen, either by more intense medical surveillance or because oestrogens induce bleeding which leads to a diagnosis.' Observations of a strong dose response relation between exposure and risk and of a fairly low prevalence of endometrial cancers diagnosed only at necropsy imply, however, that detection bias was not an important problem in previous studies. ${ }^{18}$ In Sweden health care is under public control and thus is likely to be equally available for all people regardless of socioeconomic state. The present analysis showed a duration-risk gradient, whereby risk increased significantly after long term exposure to oestrogen. Detection bias is thus unlikely to have affected the results greatly.

\section{CONCLUSIONS}

We conclude that exposure to oestradiol compounds and conjugated oestrogens without concurrent pro- gestogen is associated with an increasing risk of endometrial neoplasia with increasing duration of use (and latency of effect), with twofold to threefold increases in the risk after three or more years of use. The cyclical addition of progestogens for the greater part of the treatment may prevent or delay this increase in risk. Continuing follow up of the cohort is essential for further analyses, with enhanced statistical power, of the effects of recency, latency, and duration of the exposure to oestrogen on the risk of endometrial neoplasia.

This study was supported by research grants from the Swedish Cancer Society.

1 Hulka B. Effect of exogenous estrogens on postmenopausal women: the epidemiologic evidence. Obstet Gynecol Surv 1980;35:389-99.

Cramer DW, Knapp RC. Review of epidemiologic studies of endometrial cancer and exogenous estrogen. Obstel Gynecol 1979;54:521-6.

3 Ziel K. Estrogen's role in endometrial cancer. Obstet Gynecol 1982; 4:509-15.

4 Whitehead MI, Townsend PT, Pryse-Davies J, Ryder TA, King JB. Effects of estrogens and progestins on the biochemistry and morphology of the estrogens and progestins on the biochemistry and morphology
postmenopausal endometrium. $N$ Engl f Med 1981;305:1599-605.

5 Hammond CB, Jelovsek FR, Lee KL, et al. Effects of long-term estrogen replacement therapy. Am f Obstet Gynecol 1979;133:525-36.

6 W'acholder S, Boivin J-F. External comparisons with the case-cohort design Am f Eipidemiol 1987;126:1198-209.

7 National Corporation of Pharmacies. Statistical abstracts. Stockholm: NCP 1975: 107.

8 Schlesselman J. Sample size requirements in cohort and case-cohort studies of disease. A 7 F Epidemiol 1975;99:381-4

9 Persson I, Adami HO, Johansson EDB, Lindberg BS, Manell P, Westerholm B. A cohort study of oestrogen treatment and the risk of endometrial cancer: evaluation of method and its applicability. Eur f Clin Pharmacol 1983;25: 625-32.

10 Persson I, Adami HO, Lindberg BS, Johansson EDB, Manell P. Practice and patterns of oestrogen treatment in climacteric women in a Swedish population: a descriptive epidemiological study. Part I. Acta Obstet Gynecol Scand 1983;62:289-96.

11 Persson I, Adami HO, Lindberg BS, Johansson EDB, Manell P. CharacterPersson I, Adami HO, Lindberg BS, Johansson EDB, Manell P. Character
istics of oestrogen treated women. A descriptive epidemiological study of Swedish population. Part II. Acta Obstet Gynecol Scand 1983;62:297-302.

12 Caplan RJ, Marsh GM, Enterline PE. A generalized effective exposure modelling program for assessing dose-response in epidemiologic investigations. Comput Biomed Res 1983;16:587-96.

13 Fox $\mathrm{H}$, Buckley $\mathrm{CH}$. The endometrial hyperplasia and their relationship to endometrial neoplasia. Histopathology 1982;4:493-510.

14 Persson I, Adami HO, Lindgren A, et al. Reliability of endometrial cancer diagnoses in a Swedish cancer registry - with special reference to classification bias related to exogenous estrogens. Acta Pathol Microbiol Immunol tion bias related to exogend

15 Kleinbaum DG, Kupper LL, Morgenstern H. Stratified analysis. In: Epidemiologic research. Principles and quantitative methods. Belmont, CaliEpidemiologic research. Principles and quantitative me
fornia: Lifetime Learning Publications, 1982:320-76.

16 Bergkvist L, Adami HO, Persson I, Schairer C. Risk factors for breast and endometrial cancer in a cohort of women treated with menopausal oestrogens. Int $\mathcal{F}$ Epidemiol (in press).

17 Persson I, Adami HO, Bergkvist L. Reliability of women's histories of climacteric oestrogen treatment assessed by prescription forms. Int $\mathcal{J}$ Epidemiol 1987;16:222-8

18 Merletti F, Cole P. Detection bias and endometrial cancer. Lancet 1981;ii $579-80$.

(Accepted 26 October 1988
There seems to have of recent years been a considerable increase in the amount of alcohol consumed in the Belper Workhouse. The guardians having had their attention called to this, asked the medical officer for an explanation. This request called forth an amusing and spirited defence of the liberal prescription of alcoholic liquor to sick inmates. The medical officer declares that if there had not been this generous administration of intoxicants, the rates would have been reduced in two ways. There would have been a saving to the rates in the direct charge of the liquor used, and there would have been a saving by the premature removal of the poor people to "that bourne from whence no traveller returns." "They would die, and, in the words of the immortal Mr. Scrooge, 'materially reduce the surplus population.'" 'The medical officer insisted that his position was "unique in its impregnability." He gives, as the Hon. F. Strutt remarked at the meeting of the guardians, no statistics. A few cases, however, are narrated in proof of the necessity for alcohol. One case was that of a man brought in insensible from exposure. It does not appear to have occurred to the medical officer that there are other restoratives and restorative appliances besides alcohol. External heat, hot coffee or milk, or other liquid, aromatic spirit of ammonia, chloric ether, and compound cinnamon powder, have all been found useful in such conditions. Alcohol itself might be given in a medicinal mixture, or in such combinations as compound tincture of cardamoms, or simply in hot water. While we do not desire to question in the slightest the judiciousness of the prescriptions of intoxicants at Belper, and we are glad to note that the medical officer orders these remedies only to the sick, we cannot too strongly urge the utmost caution and deliberation in the therapeutic employment of beer, wine, and spirits in workhouses. There are so many abuses liable to arise where alcoholic drinks are freely ordered in institutions, that, wherever possible, other medicinal preparations ought to be preferred if as suitable for the case. In some very large workhouses and infirmaries very little liquor is consumed, and as no deleterious effect has been observed from the treatment on the rate of mortality, the very sparing employment of alcoholic intoxicants even as a medicine can be confidently commended to all engaged in the poor-law service. (British Medical Fournal 1889;i:31) 